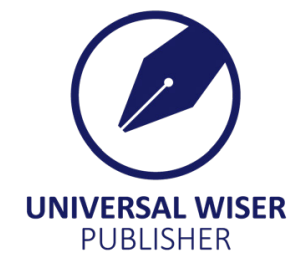

\title{
Springback Analysis of AA5754 under Warm Stamping Conditions
}

\author{
Ailing Wang ${ }^{1}$, Kai Zhong ${ }^{1}$, Omer El-Fakir ${ }^{1}$, Chaoyang Sun ${ }^{2}$, Jun Liu ${ }^{13^{*}}$, Li-Liang Wang ${ }^{1}$ \\ ${ }^{1}$ Department of Mechanical Engineering, Imperial College London, London SW7 2AZ, UK \\ ${ }^{2}$ School of Mechanical Engineering, University of Science and Technology Beijing, Beijing 100083, China \\ ${ }^{3}$ Advanced Forming Research Centre, University of Strathclyde, Glasgow PA4 9LJ, UK \\ Email: j.liu@strath.ac.uk
}

\begin{abstract}
Prediction of springback has been thoroughly investigated for cold forming processes; however with the rising prominence of lightweight materials and new forming technologies, predicting springback at elevated temperatures has become essential. In this paper, three analytical models and one empirical model were proposed to predict springback of an aluminium alloy AA5754 at warm forming conditions. The analytical models developed were based on the effect of the linear bending moment, uniform bending moment and through-thickness stress gradient respectively on springback, while the empirical model was developed using the results of L-shape bending tests. The model predictions were compared with the experiment results for various forming conditions. At room temperature, all four models had very good agreement. At elevated temperatures, the linear bending moment model was preferred for a die radius of 8mm, whereas empirical and stress gradient models were more suitable for a die radius of $4 \mathrm{~mm}$; in both cases, very close agreement was achieved where errors were within $5 \%$.
\end{abstract}

Keywords: Springback, Analytical model, Warm forming, L-shape bending, Aluminium alloy AA5754

\section{Introduction}

Aluminium alloys ${ }^{[1-5]}$ have an innate advantage for weight reduction over traditional engineering materials, e.g. steels, in the automotive industry. However, excessive springback and poor formability experienced in the cold forming condition undermines their applications.

Extensive research has been carried out to study the behaviour of aluminium alloys, such as AA2xxx ${ }^{[6-8]}$, AA $5 x x x^{[9-11]}$ and AA6 $x_{x x}{ }^{[12-14]}$ series. Springback prediction is of great importance in the design of panel components and the forming processes used to produce them from aluminium alloys, and provides a feasible way of reducing trials and errors during manufacturing. It is a challenging task to predict springback using an analytical model ${ }^{[15]}$ since the accuracy of the model depends on the constitutive laws (i.e. yielding criterion, strain and/or strain rate-hardening law) as well as other factors such as the contact and friction models. Most of the previous analytical models for springback prediction were developed for cold stamping and have been validated for a die corner radius/thickness ratio greater than $3.0(\operatorname{Rd} / t \geq 3){ }^{[16]}$. In the case of smaller $\mathrm{Rd} / \mathrm{t}$ ratios, the assumption of a linear relationship between strain and radial distance $\mathrm{y}$ from the central line of the sheet is invalid. The difficulties in modelling also arise due to the following: 1) Local thinning is severe at the bending area; 2) The radial stress or is not negligible compared to the tangential stress $\sigma \theta$; and 3 ) the central line is not always the neutral axis (NA) if the frictional force at the blank-tooling interface is considered ${ }^{[17]}$.

It is commonly accepted that springback occurs due to a material's elastic recovery. Wang ${ }^{[16]}$ proposed that (for AKDQ steel) the current bending moment acting on a blank disappears when elastic recovery takes place. A constant moment distribution was assumed in the formed part. It was found that the contribution of the flange wall region to the springback angle increased dramatically with the increase of die gap for a given material. The analytical model was in good agreement with the experimental results for $\mathrm{Rd} / \mathrm{t} \geq 3.8$. However, the model excluded the effects of thinning and tool contact. Huang et al. ${ }^{[18]}$ reported that the accuracy of the analytical models was closely related to the $\mathrm{Rd} / \mathrm{t}$ ratio by assessing a number of analytical models. It was found that the accuracy of the prediction reduced with increasing $\mathrm{Rd} /$ t ratio. Cao et al. ${ }^{[19-21]}$ proposed an explicit algorithm to predict springback for L-shape bending. Cao's model considered the effects of contact, and used a linear moment distribution along the tangential direction of the formed part, which was observed from the FE simulation results. The advantages of Cao's model are: 1) It can accurately predict springback for 
both small and large ( $\mathrm{g} / \mathrm{t} \geq 1.4$ ) die gaps; and 2) The effect of Luders bands on the true stress and strain curve was taken into account for the bending moment estimation. Cao's models have shown good agreement with the experimental results. Liveatyali et al. ${ }^{[22]}$ proposed an analytical model to predict springback for a low $\mathrm{Rd} / \mathrm{t}$ ratio down to 0.6. It was found that the analytical results were in close agreement with the experimental measurements. This model takes thinning into account and also considered the radial stress, $\sigma r$.

Empirical models were developed for the rough estimation of the springback angle. These empirical models were only valid for specific materials and testing conditions. Marciniak et al. ${ }^{[23]}$ developed an empirical moment-curvature relationship using sophisticated bending tests, which generated bending without tension to minimise the effect of tool contact. Traditional models assumed a linear relationship between the springback angle and forming parameters ${ }^{[24-25]}$. Based on those, later development has established a numerical algorithm consisting of forming and material parameters based on experimental data from V-shape and cylindrical bending tests ${ }^{[26]}$.

It was well accepted that: the springback angle decreases with increasing blankholding force (BHF) and decreasing $\mathrm{g} / \mathrm{t}$ ratio; the springback angle decreases as die corner radius ( $\mathrm{Rd})$ decreases; and the springback angle decreases as punch corner radius decreases, although it only affects springback slightly. Previously published work for springback prediction focused mainly on the cold forming condition. Most recent research work has shown that springback can be reduced at elevated temperatures. The aim of this paper is to develop effective theoretical models to predict springback at elevated temperatures, and assess their performance under difference forming conditions.

\section{Development of Springback Prediction Models}

\subsection{Model Parameters}

Based on previous research ${ }^{[19-21]}$, contact points were identified on the formed part just before unloading in the development of the prediction models, as shown in Figure 1. As springback takes place in segment OA, the studies of the effects of heat transfer, strain rate and material properties were concentrated in this segment at elevated blank and tooling temperatures.

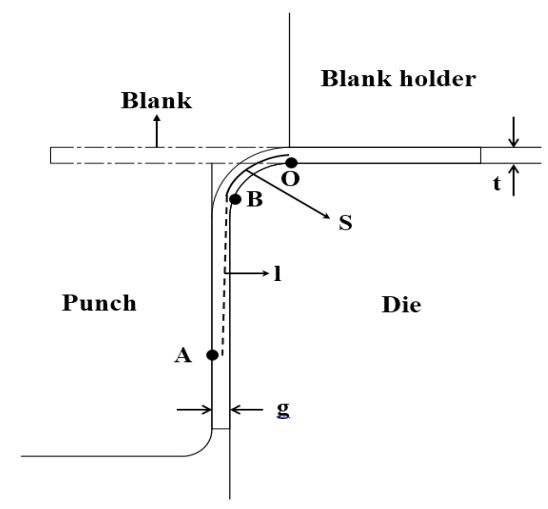

Figure 1. Schematic of three contact points at the end of the stamping process ${ }^{[20]}$

The heat transfer between the blank and the tooling during the forming process can be estimated by a constant parameter $K_{\text {loss }}(1 / s)$ according to Newton's law of cooling ${ }^{[27]}$, which provides an explicit way of estimating the average blank temperature at the end of a stamping process. By fitting to the temperature history of the Al blank, the heat transfer coefficient $(h)$ was found to be $1400 \mathrm{~W} / \mathrm{m}^{2} \mathrm{~K}$. Hence, $h=1400 \mathrm{~W} / \mathrm{m}^{2} \mathrm{~K}$ was adopted as the heat transfer coefficient in the analytical models to predict the final blank temperature $\left(T_{f}\right)$ at the end of the stamping process.

$$
\begin{aligned}
& h=K_{\text {loss }} \frac{m_{a l} C_{p, a l}}{A_{\text {contact }}} \\
& K_{\text {loss }}=-\frac{1}{t_{\text {time }}} \ln \left(\frac{T_{f}-T_{s}}{T_{i}-T_{s}}\right)
\end{aligned}
$$


where $T_{f}$ and $T_{i}$ are the final and initial temperatures of the blank respectively, $m_{a l}$ denotes the mass of the blank, $c_{p, a l}$ is the specific heat capacity, $A_{\text {contact }}$ is the effective contact area and $t_{\text {time }}$ is the duration of the stamping process. The parameters used are listed in Table 1.

Table 1. Parameters of Newton's law of cooling used to predict the blank temperature at the end of the stamping process

\begin{tabular}{llllll}
\hline$\rho_{\mathrm{al}}(\mathrm{kg} / \mathrm{m} 3)$ & $\mathrm{V}(\mathrm{mm} 3$ & $\mathrm{A}_{\text {contact }}(\mathrm{mm} 2)$ & $\mathrm{C}_{\mathrm{p} . \mathrm{al}}(\mathrm{J} / \mathrm{kgK})$ & $\mathrm{h}(\mathrm{W} / \mathrm{m} 2 \mathrm{~K})$ & $\mathrm{t}_{\text {time }}(\mathrm{s})$ \\
\hline 2680 & $150 \times 50 \times 1.5$ & $150 \times 50$ & 897 & 1400 & 0.667 \\
\hline
\end{tabular}

A power law was numerically fitted to the material flow stress. Table 2 shows the temperature-dependent material parameters used in the present research, where the strength coefficient $K$, hardening exponent $n$ and Young's modulus $E$ were described by the Arrhenius equations ${ }^{[28]}$ as follows:

$$
\begin{aligned}
& K=K_{0} \exp \left(\frac{Q_{k}}{R_{g} T}\right) \\
& n=n_{0} \exp \left(\frac{Q_{n}}{R_{g} T}\right) \\
& E=E_{0} \exp \left(\frac{Q_{E}}{R_{g} T}\right)
\end{aligned}
$$

where $K_{0}, n_{0}, E_{0}, Q_{k}, Q_{n}$ and $Q_{E}$ were constants obtained by data fitting. $T$ is the test temperature of the specimen and $R_{g}$ is the universal gas constant. The stress-strain relationships of AA5754 at $20^{\circ} \mathrm{C}$ and for temperatures of 200,250 and $300^{\circ} \mathrm{C}$ at a strain rate of $0.001 \mathrm{~s}^{-1}$ were obtained from uniaxial tensile tests as shown in Figure 2. Since the Arrhenius equation only works for high temperatures (typically $T \geq 150^{\circ} \mathrm{C}$ ), the material parameters for $T \geq 150^{\circ} \mathrm{C}$ were modelled using the Arrhenius equation while the material parameters for $20<T<150^{\circ} \mathrm{C}$ were obtained using linear interpolation. In addition, the proof stress $\sigma_{y}$ was obtained from the predicted true stress-strain curve at $0.2 \%$ strain.

Table 2. Material parameters for AA5754 at different temperatures

\begin{tabular}{ccccc}
\hline Temperature $\left({ }^{\circ} \mathrm{C}\right)$ & $K(\mathrm{MPa})$ & $n$ & $E(\mathrm{MPa})$ & $\sigma_{\mathrm{y}}(\mathrm{MPa})$ \\
\hline 20 & 512 & 0.31 & 70000 & 123 \\
150 & 365 & 0.17 & 67111 & 106 \\
200 & 212 & 0.12 & 59200 & 101 \\
250 & 140 & 0.060 & 54200 & 99 \\
300 & 97 & 0.040 & 49400 & 79 \\
\hline
\end{tabular}

\subsection{Analytical Models}

The stress-strain relationships of the analytical models developed in the present research follow Hooke's law for elastic deformation and a power hardening law for plastic deformation:

$$
\begin{aligned}
& \bar{\sigma}=E \bar{\varepsilon}, \text { for } 0<\bar{\varepsilon}<\varepsilon_{y} \\
& \bar{\sigma}=K \bar{\varepsilon}^{n}, \text { for } \varepsilon_{y}<\bar{\varepsilon}
\end{aligned}
$$

where $E$ is the Young's modulus, and $K$ and $n$ are the strength coefficient and hardening exponent respectively. If an anisotropic material is considered, according to Tresca's criterion, the yielding mechanism for anisotropic metal sheet 
under plain strain conditions is [22]:

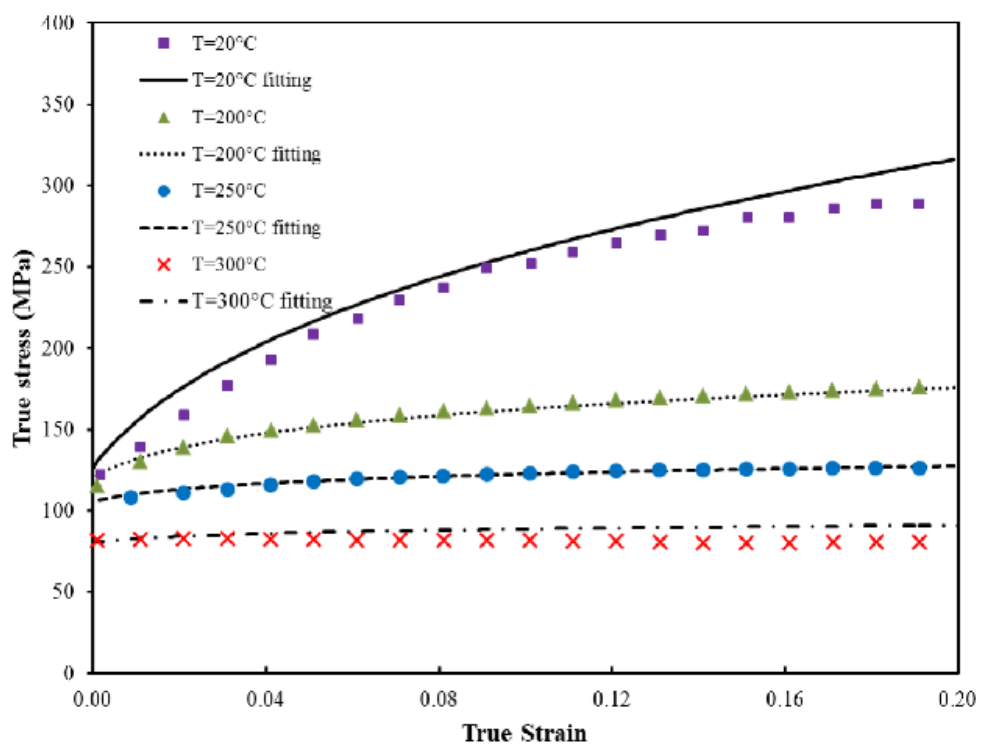

Figure 2. True stress vs. true strain data and fitting curves of AA5754

$\left|\sigma_{1}-\sigma_{3}\right|=\left|\sigma_{\theta}-\sigma_{r}\right|=\frac{1+r}{\sqrt{1+2 r}} \sigma_{T}$

where $\sigma_{T}$ is the true stress in the uniaxial tensile test. Since the magnitude of the tangential stress is much greater than the radial stress $\sigma_{r}$ (assuming the directions of and coincide with the principal axes), $\left|\sigma_{\theta}-\sigma_{r}\right|$ is approximately equal to $\left|\sigma_{\theta}\right|$. Therefore, the yield stress for plane strain is:

$$
\begin{aligned}
& \sigma_{y}^{\prime}=\sigma_{y} \frac{1+r}{\sqrt{1+2 r}} \\
& E^{\prime}=\frac{E}{1-v^{2}} \\
& \varepsilon_{y}=\frac{\sigma_{y}^{\prime}}{E^{\prime}}
\end{aligned}
$$

where $v$ is Poisson ratio. For an anisotropic material, $r$ denotes the normal R-value, which is the average of the r-values at $0^{\circ}, 45^{\circ}$ and $90^{\circ}$ to the rolling direction of the blank, shown in Table 3 .

$$
r=\frac{r_{0}+2 r_{45}+r_{90}}{4}
$$

Table 3. $R$-values at $0^{\circ}, 45^{\circ}$ and $90^{\circ}$ to the rolling direction ${ }^{[29]}$

\begin{tabular}{cccc}
\hline$r$ (at $10 \%$ strain $)$ & $r_{0}$ & $r_{45}$ & $r_{90}$ \\
\hline 0.60 & 0.69 & 0.55 & 0.61 \\
\hline
\end{tabular}

The relationship between the uniaxial and the plain strain case for the strength coefficient $K$ can be expressed as:

$$
K^{\prime}=K\left[\frac{1+r}{\sqrt{1+2 r}}\right]^{n+1}
$$


Since the hardening exponent $n$ for AA5754 is always less than or equal to 0.31 , the value of $K$ can be estimated as following:

$$
K^{\prime}=K \frac{1+r}{\sqrt{1+2 r}}
$$

The maximum true strain ( $\varepsilon_{T}$ in Fig.3) and engineering strain $\left(\varepsilon_{\theta}\right)$ of bending are calculated by using Eqs. 15 and 16.

$$
\begin{aligned}
& \varepsilon_{T}=\ln \left(\frac{R_{n}+y}{R_{n}}\right) \\
& \varepsilon_{e}=\kappa y
\end{aligned}
$$

where $R_{n}$ is the radius of the neutral axis, curvature $\kappa$ is obtained from $1 / R_{n}$, and $y$ denotes the distance from the neutral axis. In the case of a large bending radius $R$, the difference between the true strain and engineering strain is small. The engineering strain is easier to substitute into the algorithm. However, in the case of a small bending radius, true strain instead of engineering strain has to be used, and can be derived using Eq. ${ }^{[19]}$ :

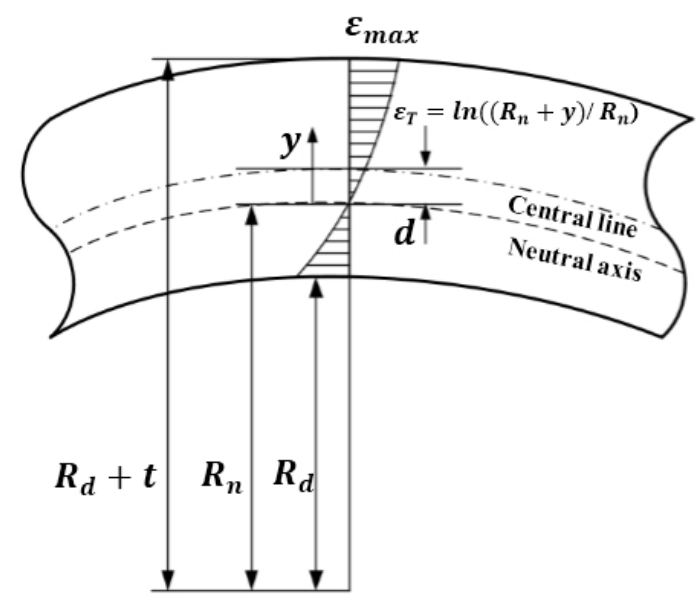

Figure 3. True strain along thickness direction (not in scale)

$$
\varepsilon_{T}=\ln \left(1+\varepsilon_{e}\right)=\varepsilon_{e}-\frac{\varepsilon_{e}^{2}}{2}+\frac{\varepsilon_{e}^{3}}{3}-\frac{\varepsilon_{e}^{4}}{4} \ldots
$$

The central line (mid-plane) of the blank is not necessarily the neural axis if friction is considered during the bending process. In the L-shape bending test, the neutral axis shifts towards the inner bending surface as shown in Figure 3 . The amount of shift $d$, can be estimated from the maximum strain:

$$
\begin{aligned}
& R_{n}=\frac{\left(R_{d}+t\right)}{\exp \left(\varepsilon_{\max }\right)} \\
& d=\left(R_{d}+\frac{t}{2}\right)-R_{n} \\
& d_{o}=\frac{t}{2}+d
\end{aligned}
$$




$$
d_{i}=\frac{t}{2}-d
$$

where $d_{o}$ and $d_{i}$ are the distance from the outer and inner bending surfaces, respectively.

The general form of the bending moment through a bending cross-section is shown in Eq. 22, where $x 1$ and $x 2$ are the outer and inner surfaces of the cross-section.

$$
M=\int_{x 2}^{x 1} \sigma(y) \cdot y d y
$$

The bending moment (per unit width) of an elasto-plastic material can be split into an elastic bending moment $M_{e}$ in the elastic zone and a plastic bending moment $M_{p}$ in the plastic zone. In the presence of an axial load, i.e. frictional force, the neutral axis shifts downward by distance $d$. The fibre position $y_{1}$ corresponds to the yield strain $\varepsilon_{y}$.

For simplicity, the $M_{p}$ is decomposed into $M_{p 1}$ for $d \leq y \leq d_{o}, M_{p 2}$ for $y 1<y<d$ and $M_{p 3}$ for $-d_{i} \leq y \leq y_{1}$. The $M_{e}$ is decomposed into $M_{e 1}$ for $0 \leq y \leq y_{1}$ and $M_{e 2}$ for $-y_{1}<y \leq 0$ as shown in Figure 4 . All moments are taken about the central line so that the moment due to the axial load is set to zero.

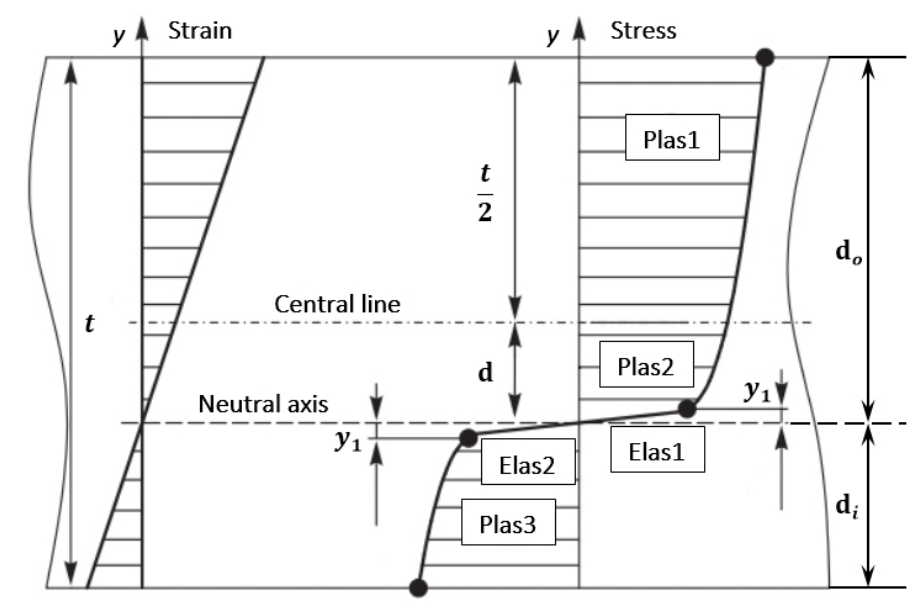

Figure 4. Demonstration of elastic core, plastic zone and shift of neutral axis during bending process

From Eq. 23, position $y_{1}$ is derived as:

$y_{1}=\frac{\varepsilon_{y}}{\kappa}$

The bending moment for each section is calculated using Eq. 22. The elastic bending moments are:

$$
\begin{aligned}
& M_{e 1}=\int_{0}^{y_{1}} E^{\prime} \cdot \kappa y \cdot(y-d) d y \\
& M_{e 2}=\int_{0}^{y_{1}} E^{\prime} \cdot \kappa y \cdot(y+d) d y
\end{aligned}
$$

The total elastic bending moment is: 


$$
M_{e}=M_{e 1}+M_{e 2}
$$

The plastic bending moment sections are as follows:

$$
\begin{aligned}
& M_{p 1}=\int_{d}^{d_{o}} K \cdot(\kappa y)^{n} \cdot(y-d) d y \\
& M_{p 2}=\int_{y_{1}}^{d} K \cdot(\kappa y)^{n} \cdot(y-d) d y \\
& M_{p 3}=\int_{y_{1}}^{d_{i}} K \cdot(\kappa y)^{n} \cdot(y+d) d y
\end{aligned}
$$

The total plastic bending moment is:

$$
M_{p}=M_{p 1}+M_{p 2}+M_{p 3}
$$

The total bending moment is the sum of the elastic and plastic bending moments:

$$
M=M_{e}+M_{p}
$$

The engineering strain $\varepsilon_{e}=\kappa y$ was used in the derivations, since the die corner radius to thickness ratio is not significantly less than 3.0 as reported by Livatyali et al. ${ }^{[22]}$. In this paper the smallest $R_{d} / t$ ratio is set to be 2.7 .

\subsubsection{Linear Bending Moment Model}

It is widely accepted that the amount of springback is directly related to the moment distribution along the tangential direction of the formed part before unloading. In the linear bending moment model, the bending moment is assumed to vary linearly from points A to B, reaching a peak at B and then decrease linearly to $\mathrm{O}$, as illustrated in Figure 5. The same bending moment distribution was used in Cao's linear bending model ${ }^{[20]}$.

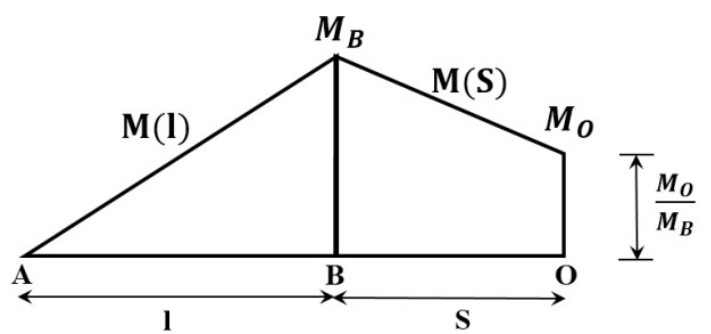

Figure 5. Schematics of linear bending moment distribution of the model

The springback angle $\Delta \theta$ proposed by Cao et al. ${ }^{[20]}$ is the sum of the springback angles $\theta_{l}$ and $\theta_{s}$ which arise due to the elastic recovery of the straight and curved parts of the blank, and are expressed as:

$$
\theta_{l}=\frac{1}{2} \frac{l \cdot \varphi_{B} \cdot \gamma_{B}}{R_{n}}
$$


$\theta_{S}=\frac{S\left(1+M^{\prime}\right) \varepsilon_{y} \gamma_{B}}{t}$

where and $\gamma_{\mathrm{B}}$ are non-dimensional parameters, as follows:

$$
\begin{gathered}
\gamma_{B}=\frac{M_{B}}{M_{y}} \\
M^{\prime}=\frac{M_{o}}{M_{B}}
\end{gathered}
$$

Cao's model was designed to predict springback at room temperature. However, at elevated temperatures $\left(T_{b} \geq 150^{\circ} \mathrm{C}\right)$, $M^{\prime}\left(M_{O} / M_{B}\right)$ varies due to the large temperature variation from point $O$, so the value of $M^{\prime}$ 'was studied.

In this paper, modifications were made based on Cao's assumption to better fit the springback prediction at elevated temperatures. An elasto-plastic material model was used, and Hill's anisotropic model was adopted. A shift in the neutral axis (NA) was expected to occur, and the amount of shift $d$ was estimated using Eqs. 18 and 19, where the maximum strain $\varepsilon_{\max }$ is presented in Table 4. $\varepsilon_{\max }$ at the outer surface of the blank was obtained from the FE simulation results published in the author's previous work ${ }^{[30]}$. It was found that the increasing blank temperature led to an increased shift of the neutral axis. The tangential stress $\sigma_{\theta}$ coincided with the axis of major principal stress, while the magnitude of the radial stress $\sigma_{r}$ was negligible compared to $\sigma_{\theta}$. The planes normal to the surface of the blank were assumed to remain plane throughout the bending process.

Table 4 summarizes the parameters used in the linear bending moment model at three blank temperatures. The values of $M^{\prime}$ and maximum strain $\varepsilon_{\max }$ at other blank temperatures were calculated using linear interpolation based on the values displayed.

Table 4. Parameters used in the linear bending moment model for different temperatures

\begin{tabular}{ccc}
\hline Forming conditions & $M^{\prime}$ & $\varepsilon_{\max }$ \\
\hline Cold forming, $\mathrm{T}_{\text {blank }}=20^{\circ} \mathrm{C}, \mathrm{R}=4 \mathrm{~mm}$ & $\mathrm{M}_{\mathrm{O}} / \mathrm{M}_{\mathrm{B}}$ & 0.147 (no NA shift) \\
Cold forming, $\mathrm{T}_{\text {blank }}=150^{\circ} \mathrm{C}, \mathrm{R}=4 \mathrm{~mm}$ & 0.3 & 0.192 \\
Cold forming, $\mathrm{T}_{\text {blank }}=250^{\circ} \mathrm{C}, \mathrm{R}=4 \mathrm{~mm}$ & 0.1 & 0.210 \\
Cold forming, $\mathrm{T}_{\text {blank }}=300^{\circ} \mathrm{C}, \mathrm{R}=4 \mathrm{~mm}$ & 0 & 0.219 \\
Warm forming, $\mathrm{T}_{\text {blank }}=20^{\circ} \mathrm{C}, \mathrm{R}=4 \mathrm{~mm}$ & $\mathrm{M}_{\mathrm{O}} / \mathrm{M}_{\mathrm{B}}$ & 0.147 (no NA shift) \\
Warm forming, $\mathrm{T}_{\text {blank }}=150^{\circ} \mathrm{C}, \mathrm{R}=4 \mathrm{~mm}$ & 0.3 & 0.192 \\
Warm forming, $\mathrm{T}_{\text {blank }}=250^{\circ} \mathrm{C}, \mathrm{R}=4 \mathrm{~mm}$ & 0.1 & 0.210 \\
Warm forming, $\mathrm{T}_{\text {blank }}=300^{\circ} \mathrm{C}, \mathrm{R}=4 \mathrm{~mm}$ & 0 & 0.219 \\
Cold forming, $\mathrm{T}_{\text {blank }}=20^{\circ} \mathrm{C}, \mathrm{R}=8 \mathrm{~mm}$ & $\mathrm{M}_{\mathrm{O}} / \mathrm{M}_{\mathrm{B}}$ & 0.0822 (no NA shift) \\
Cold forming, $\mathrm{T}_{\text {blank }}=150^{\circ} \mathrm{C}, \mathrm{R}=8 \mathrm{~mm}$ & 0.9 & 0.095 \\
Cold forming, $\mathrm{T}_{\text {blank }}=250^{\circ} \mathrm{C}, \mathrm{R}=8 \mathrm{~mm}$ & 0.7 & 0.10 \\
Cold forming, $\mathrm{T}_{\text {blank }}=150^{\circ} \mathrm{C}, \mathrm{R}=8 \mathrm{~mm}$ & 0.6 & 0.1025 \\
\hline
\end{tabular}

The explicit solution procedures of this model were as follows: The final average blank temperature $T_{f}$ was first determined using Newton's law of cooling (Eqs. 1 and 2); the material parameters were estimated at $T_{f}$ using the Arrhenius equations for $T_{b} \geq 150^{\circ} \mathrm{C}$ and linear interpolation for $20^{\circ} \mathrm{C}<T_{b}<150^{\circ} \mathrm{C}$ (Table 2); the shift of the neutral axis was then estimated from the maximum strain at the outer fibre (Eqs. 18 and 19 and Table 4); the bending moment $M_{B}$ was finally calculated at contact point B, based on the steps established previously. The geometry parameters such as $\varphi_{B}, \eta_{B}$ and $\psi_{B}$ (the formulations for which can be found in [20]) and the lengths of the curved part $S$ and straight part $l$ were then estimated. Finally the springback angle $\Delta \theta$ was determined from the sum of the springback angles $\theta_{l}$ and $\theta_{s}$, as shown in Eqs. 32 and 33. 


\subsubsection{Uniform Bending Moment Model}

Instead of a linear moment distribution, a uniform bending moment model was also proposed based on the assumption that a uniform bending moment $M$ develops over the curved part $S$ of the formed blank during the L-shape bending process. Meanwhile, no bending moment develops over the straight part $l$ as shown in Figure 6.

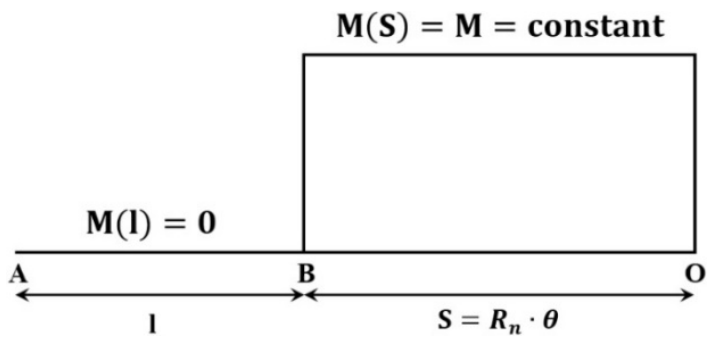

Figure 6. Schematic of uniform bending moment

After unloading, this bending moment is released and the formed blank would springback to a new equilibrium geometry. The magnitude of the bending moment $\mathrm{M}$ is equal to the change in the bending moment $\Delta \mathrm{M}$ :

$$
M=\Delta M
$$

where $\Delta \mathrm{M}$ is generated due to the change in the tangential stresses $\Delta \sigma_{\theta}$ in the internal fibres of the blank that resulted from the elastic unloading.

$$
\begin{aligned}
& \Delta \sigma_{\theta}=E^{\prime} \Delta \varepsilon_{\theta} \\
& \Delta \varepsilon_{\theta}=\frac{y}{R_{n}}-\frac{y}{R_{n}^{\prime}}=y \cdot \Delta\left(\frac{1}{R_{n}}\right)
\end{aligned}
$$

where $R_{n}$ and $R_{n}$ ' are the bending radii at the neutral axis before and after unloading, and is the Young's modulus in the plane strain condition. According to pure bending theory, the change in the bending moment per unit width can be expressed as:

$$
\Delta M=M=\int_{-\frac{t}{2}}^{\frac{t}{2}} \Delta \sigma_{\theta} \cdot y d y=\frac{E^{\prime} t^{3}}{12} \cdot \Delta\left(\frac{1}{R_{n}}\right)
$$

It is also known that the length of the curved part $S$ at the neutral axis remains constant before and after unloading. Therefore the infinitesimal change of curvature $d\left(1 / R_{n}\right)$ can be deduced as:

$$
\begin{aligned}
& S=\theta \cdot R_{n} \\
& d\left(\frac{1}{R_{n}}\right)=\frac{d \theta}{S}
\end{aligned}
$$

Substituting Eq. 41 into Eq. 39, the springback angle $\Delta \theta$ can be calculated using:

$$
\Delta \theta=\frac{12 M}{E^{\prime} t^{3}} \cdot R_{n} \theta
$$

The bending moment $M$ consists of the elastic bending moment $M_{e}$ and plastic bending moment $M_{e}$, where $M_{p}$ is 
obtained using Eq. 30. As in the linear bending moment model, the shift of the neutral axis is taken into account based on the maximum outer fibre strain shown in Table 5. According to the simulation results, the bending angle $\theta$ was slightly less than $90^{\circ}$. Although the explicit value for $\theta$ is unknown, $\theta$ can be considered as $90^{\circ}$ in this model when predicting the springback angle.

For the uniform bending moment model, the total bending moment $M$ is the sum of $M_{e}$ and $M_{e}$, and the springback angle $\Delta \theta$ is determined using Eq. 42.

Table 5. Parameters used in the uniform bending moment model for different temperatures

\begin{tabular}{ccc}
\hline Forming conditions & $\theta\left(^{\circ}\right)$ & $\varepsilon_{\max }$ \\
\hline Cold forming, $\mathrm{T}_{\text {blank }}=20^{\circ} \mathrm{C}, \mathrm{R}=4 \mathrm{~mm}$ & 90 & 0.147 (no NA shift) \\
Cold forming, $\mathrm{T}_{\text {blank }}=150^{\circ} \mathrm{C}, \mathrm{R}=4 \mathrm{~mm}$ & 90 & 0.195 \\
Cold forming, $\mathrm{T}_{\text {blank }}=250^{\circ} \mathrm{C}, \mathrm{R}=4 \mathrm{~mm}$ & 90 & 0.21 \\
Cold forming, $\mathrm{T}_{\text {blank }}=300^{\circ} \mathrm{C}, \mathrm{R}=4 \mathrm{~mm}$ & 90 & 0.219 \\
Warm forming, $\mathrm{T}_{\text {blank }}=20^{\circ} \mathrm{C}, \mathrm{R}=4 \mathrm{~mm}$ & 90 & 0.147 (no NA shift) \\
Warm forming, $\mathrm{T}_{\text {blank }}=150^{\circ} \mathrm{C}, \mathrm{R}=4 \mathrm{~mm}$ & 90 & 0.195 \\
Warm forming, $\mathrm{T}_{\text {blank }}=250^{\circ} \mathrm{C}, \mathrm{R}=4 \mathrm{~mm}$ & 90 & 0.21 \\
Warm forming, $\mathrm{T}_{\text {blank }}=300^{\circ} \mathrm{C}, \mathrm{R}=4 \mathrm{~mm}$ & 90 & 0.219 \\
Cold forming, $\mathrm{T}_{\text {blank }}=20^{\circ} \mathrm{C}, \mathrm{R}=8 \mathrm{~mm}$ & 90 & 0.0822 (no NA shift) \\
Cold forming, $\mathrm{T}_{\text {blank }}=150^{\circ} \mathrm{C}, \mathrm{R}=8 \mathrm{~mm}$ & 90 & 0.090 \\
Cold forming, $\mathrm{T}_{\text {blank }}=250^{\circ} \mathrm{C}, \mathrm{R}=8 \mathrm{~mm}$ & 90 & 0.095 \\
Cold forming, $\mathrm{T}_{\text {blank }}=300^{\circ} \mathrm{C}, \mathrm{R}=8 \mathrm{~mm}$ & 90 & 0.1025 \\
\hline
\end{tabular}

\subsubsection{Stress Gradient Model}

The stress gradient model was developed on the basis of the through-thickness stress gradient of the formed blank before unloading. The authors previously found that a linear relationship existed between the stress gradient and the springback angle regardless of the type of loading, blank geometry and forming conditions ${ }^{[20]}$. For the aluminium alloy AA5754, the best linear fit between the springback angle and stress gradient was found as: Springback angle $=0.178 \times$ stress gradient, where the stress gradient was defined as the ratio between the average tangential stress difference and the thickness of the blank:

$$
\text { stress gradient }=\frac{\text { average through }- \text { thickness stress difference }}{\text { average blank thickness }}
$$

It was found that the average tangential stress difference was a linear function of the corresponding tangential stress at the end of the stamping process at elevated temperatures $\left(T_{b} \geq 150^{\circ} \mathrm{C}\right)$. This relation can be expressed as

$$
\text { average through-thickness stress difference }=\frac{\sigma_{\theta, \text { stamping }}}{F}
$$

where the parameter $F$ is ' 15 ' when $R_{d}=4 \mathrm{~mm}$ and ' 5.5 ' when $R_{d}=8 \mathrm{~mm}$, and $\sigma_{\theta, \text { stamping }}$ is calculated from the material parameters at the end of the stamping process in Table 2 using:

$$
\begin{gathered}
\sigma_{\theta, \text { stamping }}=K^{\prime} \cdot \varepsilon_{\theta}{ }^{n} \\
\varepsilon_{\theta}=\ln \left(1+\frac{\frac{t}{2}}{R_{d}+\frac{t}{2}}\right)
\end{gathered}
$$

where $t$ is the thickness of the blank and $R_{d}$ is the radius of the die corner. It was assumed that there was no shift of the neutral axis (i.e. friction was not considered) and that the thickness of the blank remained constant throughout the 
processes (i.e. the influence of thinning was not considered).

The explicit solution procedures of this model are as follows: the final blank temperature $T_{f}$ and material parameters at $T_{f}$ were estimated using the same method as in the linear and constant bending moment models; the average tangential stress difference was then estimated using Eq. 43 by substituting in the value of $\sigma_{\theta, \text { stamping }}$ calculated from Eqs. 44 ; finally the springback angle was determined using the stress gradient relationship.

\subsubsection{Empirical Model}

An empirical model was proposed for the L-shape bending process based on curve fitting of the experimental results to predict the springback angles after unloading.

The expression for this model is given as:

$$
\theta=A \cdot\left(\frac{R_{d}}{t}\right)^{m} \cdot\left(\frac{g}{t}\right)^{n} \cdot \ln \left(T_{\text {blank }}\right)^{j}+B
$$

where the term $R_{d} / t$ is the die corner radius to blank thickness ratio and the term $g / t$ is the die gap to blank thickness ratio. $T_{\text {blank }}$ denotes the initial blank temperature in Kelvins. $A, B, \mathrm{j}, n$ and $m$ are model constants and their values are indicated in Table 6.

Table 6. Constants of the empirical model

\begin{tabular}{cc}
\hline Model constants & Values \\
\hline $\mathrm{A}$ & 119.5 \\
$\mathrm{~B}$ & -28.62 (cold) -28.84 (warm) \\
$j$ & -0.8 \\
$n$ & 0.19 \\
$m$ & 0.07 \\
\hline
\end{tabular}

\section{Results and Discussion}

Figure 7(a) shows the effect of blank temperature on springback for a small die corner radius $\left(R_{d}=4 \mathrm{~mm}\right)$ when the temperatures of the die, punch and blankholder were initially cold (room temperature). In general, the predicted results from all four models have shown very good agreement with the experimental data, particularly at the cold forming condition where the blank is initially at room temperature. At warm forming conditions $\left(T_{\text {blank }}>20^{\circ} \mathrm{C}\right)$, the stress gradient model and empirical model have very good agreement, both with maximum error within $5 \%$. The uniform and linear bending moment models have shown an overestimation of the springback angle at elevated blank temperatures. In the cases of elevated blank temperatures, the local temperature varies with curvilinear distance along the blank at the flange area during stamping, which leads to varying material parameters at the flange area at elevated temperatures.

Figure 7(b) shows the effect of blank temperature on springback for a small die corner radius $\left(\mathrm{R}_{\mathrm{d}}=4 \mathrm{~mm}\right)$ when the hot die/punch forming condition was applied. At warm forming conditions $\left(\mathrm{T}_{\text {blank }} \geq 150^{\circ} \mathrm{C}\right)$, the uniform and linear bending moment models have over-predicted springback, whereas the stress gradient and empirical model have shown accurate results. The maximum absolute error for the stress gradient model and empirical model are $0.04^{\circ}$ and $0.06^{\circ}$, respectively, representing a percentage error of $2 \%$ and $3 \%$. For a small bending radius (i.e. $\mathrm{R}=4 \mathrm{~mm}$ ), stress gradient and empirical models are preferred over bending moment models for predicting springback at elevated temperatures for both cold and hot dies. 

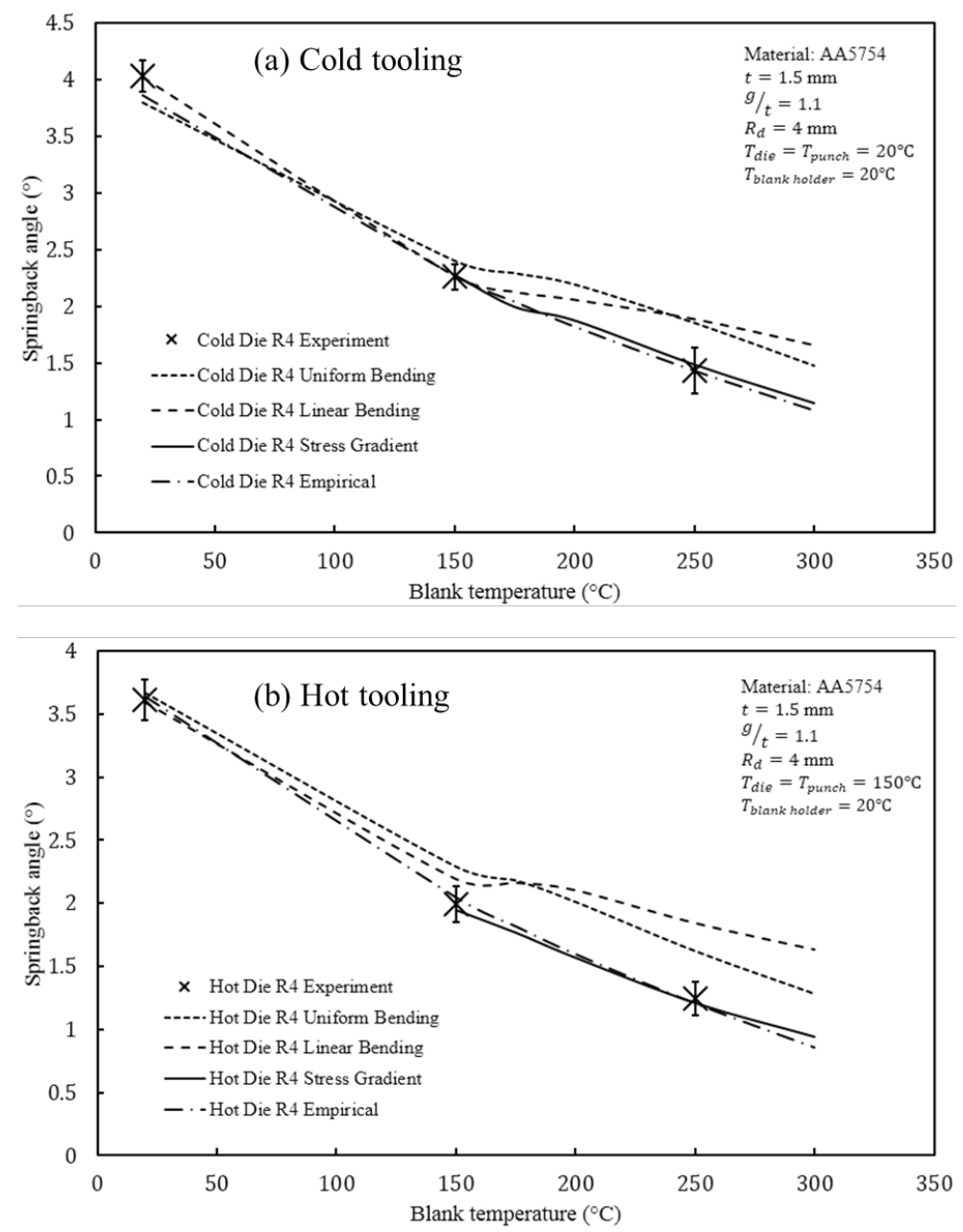

Figure 7. Comparison of the springback angles between the analytical/empirical models and the experimental results $(R=4 \mathrm{~mm}, g / t=1.1):(a)$ cold die/punch forming condition $\left(T_{\text {tooling }}=20^{\circ} \mathrm{C}\right)$ and (b) hot die/punch forming condition $\left(T_{\text {tooling }}=150^{\circ} \mathrm{C}\right)$

Figure 8(a) shows the effect of blank temperature on springback for a large die corner radius $\left(\mathrm{R}_{\mathrm{d}}=8 \mathrm{~mm}\right)$ when the temperatures of the die, punch and blankholder were initially cold. The linear bending moment model and the stress gradient model have accurately predicted springback, whereas the uniform bending moment model and the empirical model have shown an underestimation. The linear bending moment model gives the best agreement in the case of $\mathrm{R}=8 \mathrm{~mm}$ in the presence of a cold die; the errors were within $5 \%$ for all temperature conditions considered.

Figure $8(b)$ shows the effect of die gap on springback for a small die corner radius $\left(\mathrm{R}_{\mathrm{d}}=4 \mathrm{~mm}\right)$ when the cold die/ punch forming condition was applied. Only the linear bending moment and empirical models could be used to predict springback as a function of $g / t$ (die gap/thickness) in the present work. The springback predictions were in very good agreement with the experimental results. For the commonly used $g / t$ ratio of 1.1, the errors from both models were within $5 \%$, with the linear bending moment model yielding an error as small as $0.01^{\circ}$.

It can be seen from the Figs. 7-8 that all models could yield accurate results at room temperature when the initial blank temperature $T_{\text {blank }}$ was $20^{\circ} \mathrm{C}$. As $T_{\text {blank }}$ increased, prediction errors were observed in some of the models. For the linear and uniform bending moment models, the maximum strain at the outer surface of the blank at elevated temperatures was obtained from FE simulations to deduce the shift of the neutral axis. Hence the model could be refined to obtain an analytical solution for the shift distance. The constants ' $\mathrm{F}$ ' in the stress gradient model were determined for corresponding $R_{d} / t$ ratios for AA5754 when $g / t=1.1$. Further work can be conducted to study these constants for different forming conditions and materials. A comprehensive empirical model could then be developed based on the current one to evaluate springback under different forming conditions. 

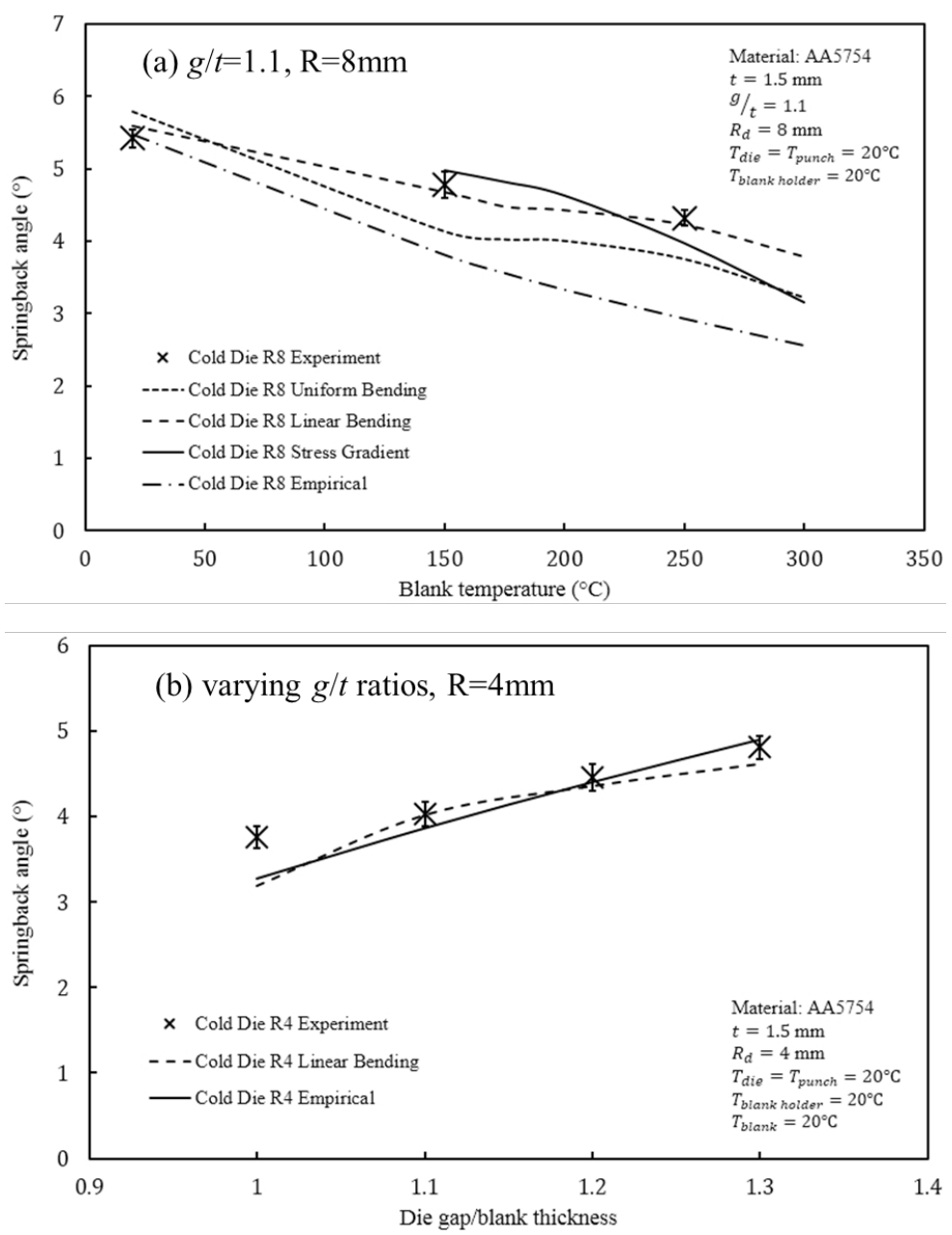

Figure 8. Comparison of the springback angles between the analytical/empirical models and the experimental results at cold forming conditions: (a) $g / t=1.1, R=8 \mathrm{~mm}$ and (b) varying $g / t$ ratios, $R=4 \mathrm{~mm}$

\section{Conclusions}

In the present research, four analytical models were developed to predict the springback of an aluminium alloy at warm forming conditions. The overall performance of each model was evaluated using the experimental results and the following conclusions could be drawn:

1. The linear bending moment model had accurately predicted the effect of the blank temperature on springback angle in the case of $R_{d}=8 \mathrm{~mm}$, with all errors were within $5 \%$. However, springback angle for elevated temperatures in the case of $R_{d}=4 \mathrm{~mm}$ was over predicted. Nevertheless, this model has successfully predicted springback for varying $g / t$ ratios.

2. Under the uniform bending moment model, springback for $R_{d}=4 \mathrm{~mm}$ was over-predicted and springback for $R_{d}=8$ $\mathrm{mm}$ was under-predicted at elevated blank temperatures. Moreover, the inherent disadvantage of this model was that it cannot be used to predict springback at varying $g / t$ ratios.

3. The stress gradient model had achieved a close agreement with the experimental results for the study of the effect of blank temperature. It had accurately predicted the springback at elevated blank temperatures $\left(T_{\text {blank }} \geq 150^{\circ} \mathrm{C}\right)$, where errors were within $10 \%$ for all temperatures regardless of die temperature and die radius. Similar to the uniform bending moment model, this model could not provide springback prediction for varying $g / t$ ratios.

4. The empirical model had successfully predicted springback in the case of $R_{d}=4 \mathrm{~mm}$ for both varying $g / t$ ratios and temperatures, where all errors were within $5 \%$ for springback prediction at elevated temperatures. However, this model is less suitable for $\mathrm{R}_{\mathrm{d}}=8 \mathrm{~mm}$ as it under-predicted springback. 


\section{Conflict of interest}

The authors declare no conflict of interest.

\section{References}

[1] Liu J, Tan, MJ, Jarfors, AEW, et al. Formability in AA5083 and AA6061 alloys for light weight applications. Materials \& Design 2010; 31: 66-70.

[2] Liu J, Tan MJ, Aue-u-lan Y, et al. Superplastic-like forming of non-superplastic AA5083 combined with mechanical pre-forming. International Journal of Advanced Manufacturing Technology 2011; 52: 123-129.

[3] Liu J, Wang L, Lee J, et al. 2015. Size-dependent mechanical properties in AA6082 tailor welded specimens. Journal of Materials Processing Technology 2015; 224: 169-180.

[4] Wang A, Liu J, Gao H, et al. Hot stamping of AA6082 tailor welded blanks: Experiments and knowledge-based cloud - finite element (KBC-FE) simulation. Journal of Materials Processing Technology 2017; 250: 228-238.

[5] Liu, J, Wang A, Gao H, et al. Transition of failure mode in hot stamping of AA6082 tailor welded blanks. Journal of Materials Processing Technology 2018; 257: 33-44.

[6] McMurray RJ, Leacock AG, Brown, D. The Influence of Cladding on the Springback of 2024-T3 Aluminium Alloy. Key Engineering Materials 2007; 340-341: 853-858.

[7] Deng L, Wang X, Jin J, et al. Springback and hardness of aluminum alloy sheet part manufactured by warm forming process using non-isothermal dies. Procedia Engineering 2017; 207: 2388-2393.

[8] Churiaque C, Sánchez-Amaya JM, Caamaño, F, et al. Springback Estimation in the Hydroforming Process of UNS A92024-T3 Aluminum Alloy by FEM Simulations. Metals 2018; 8: 404-420.

[9] Kim HS, Koç M. Numerical investigations on springback characteristics of aluminum sheet metal alloys in warm forming conditions. Journal of Materials Processing Technology. 2008; 204(1): 370-383.

[10] Ozturk F, Toros S, Pekel H. Evaluation of tensile behaviour of 5754 aluminium-magnesium alloy at cold and warm temperatures. Materials Science and Technology 2009; 25(7): 919-924.

[11] Laurent H, Grèze R, Oliveira MC, et al. Numerical study of springback using the split-ring test for an AA5754 aluminum alloy. Finite Elements in Analysis and Design. 2010; 46(9): 751-759.

[12] Adnan MF, Abdullah, AB, Samad, Z. Effect of annealing, thickness ratio and bend angle on springback of AA6061-T6 with non-uniform thickness section. MATEC Web Conferences 2017; 90: 01002.

[13] Xue X, Liao J, Vincze G, et al. Control strategy of twist springback for aluminium alloy hybrid thin-walled tube under mandrel-rotary draw bending. International Journal of Material Forming 2018; 11: 311-323.

[14] Cai ZH, Batthyány P, Dhawan S, et al. Study of Springback for High Strength Aluminium Alloys Under Hot Stamping, Advanced High Strength Steel and Press Hardening 2019; 4: 117-121.

[15] Uemori T, Fujii K, Nakata T, et al. Springback Analysis of Aluminum Alloy Sheet Metals by Yoshida-Uemori Model. Key Engineering Materials 2017; 725: 566-571.

[16] Wang NM. Predicting the effect of die gap of flange springback. Proceedings of the 13th IDDRG Congress. Melbourne: 1984. 133-147.

[17] Zhang RY, Zhao GY, Guo ZH, et al. Effects of material parameters on springback of 5052 aluminium alloy sections with hat profile in rotary draw bending. The International Journal of Advanced Manufacturing Technology. 2015; 80(5): 1067-1075.

[18] Huang M, Gerdee JC. Springback of doubly curved developable sheet metal surface-an overview. SAE Technical Paper Series 1994; 940938: 125-138.

[19] Buranathiti T, Cao J. An effective analytical model for springback prediction in straight flanging processes. International Journal of Materials \& Product Technology 2004; 21: 137-153.

[20] Viswanathan V, Kinsey B, Cao J. Experimental Implementation of Neural Network Springback Control for Sheet Metal Forming. Journal of Engineering Materials and Technology. 2003; 125(2): 141-147.

[21] Song N, Qian D, Cao J, et al. Effective models for prediction of springback in flanging. Journal of Engineering Materials and Technology-Transactions of the ASME 2001; 123: 456-461.

[22] Livatyali H, Kinzel GL, Altan T. Computer aided die design of straight flanging using approximate numerical analysis. Journal of Materials Processing Technology 2003; 142: 532-543.

[23] Marciniak Z, Duncan JL, Hu SJ. Mechanics of Sheet Metal Forming. Oxford: Butterworth-Heinemann, 2002.

[24] Levy BS. Empirically derived equations for predicting springback in bending. Journal of Applied Metalworking 1984; 3(2): 135-141.

[25] Tan Z, Persson B, Magnusson C. An empiric model for controlling springback in V-die bending of sheet metals. Journal of materials Processing Technology 1992; 34: 449-455. 
[26] Mullan HB. Improved prediction of springback on final formed components. Journal of Materials Processing Technology 2004; 153: 464-471.

[27] Rogers GFC, Mayhew YR. Engineering Thermodynamics: Work and Heat Transfer (4th ed.). London: Longman, 1992.

[28] Mohamed MS, Foster AD, Lin J, et al. Investigation of deformation and failure features of AA6082: Experimentation and modelling. International Journal of Machine Tools \& Manufacture 2012; 53: 27-38.

[29] Wang L, Shi Z, Mohamed MS, et al. Isothermal tensile tests under warm forming conditions. Report to Jaguar Land Rover. London: 2012.

[30] Wang A, Zhong K, El-Fakir O, et al. Springback analysis of AA5754 after hot stamping: experiments and FE modelling. The International Journal of Advanced Manufacturing Technology 2017; 89(5-8): 1339-1352. 